\title{
INNOVATIONS WITH INCUBATION: RECOMMENDATIONS FOR CORPORATE INCUBATORS AND CORPORATE ACCELERATORS - BASED ON AN EMPIRICAL STUDY
}

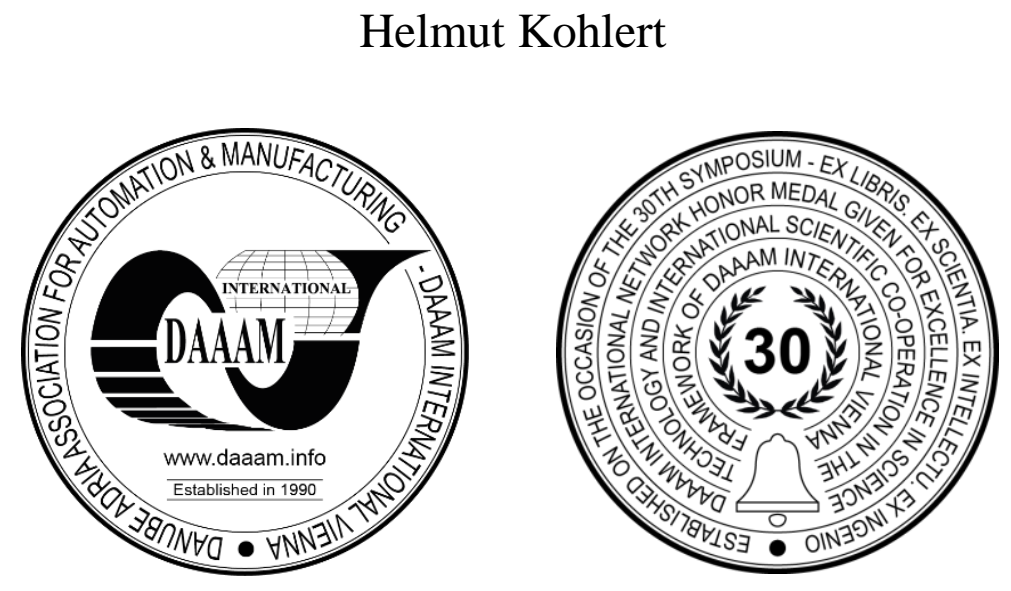

This Publication has to be referred as: Kohlert, H[elmut] (2019). Innovations with Incubation: Recommendations for Corporate Incubators and Corporate Accelerators - Based on an Empirical Study, Proceedings of the 30th DAAAM International Symposium, pp.0733-0737, B. Katalinic (Ed.), Published by DAAAM International, ISBN 978-3-90273422-8, ISSN 1726-9679, Vienna, Austria

DOI: $10.2507 / 30$ th.daaam.proceedings.100

\begin{abstract}
This study is dealing with the experiences of Corporate Incubators and Corporate Accelerators in Germany in the technical context. In this study corporate incubators are companies which are supporting start-ups in an early stage with infrastructure needed or with an appropriate and supporting frame. Team and business idea are normally not complete and not fully configured in this stage. Corporate accelerators are companies which are engaged in precise business ideas, often a prototype is available. They offer access to their own company, to investors and to mentors. Many big German companies are engaged at least in one of the both. Their objective is the identification of new business ideas areas, which have a low or even no relation to the existing „Value Propositions“. The ultimate objective is the start-up as a tool to escape from the daily business routines and to act partially like an Entrepreneur. For Entrepreneurs and their start-ups it is an opportunity to link with the big companies, to meet a first reference customer there and to overcome the financial obstacles. Based on an empirical study, recommendations will be presented how to use incubators and accelerators efficiently for companies in a technical context.
\end{abstract}

Keywords: Innovation; Corporate Incubator; Corporate Accelerators; new ideas; start-ups; Value Propositions

\section{Challenge for Corporations}

Companies have experienced in the past that technology driven newcomers were entering into their traditional markets, mostly disruptive with a bigger and faster impact than ever. As these start-ups were not really respected at the beginning they were able to challenge a well-established company with something new successfully. Often the "dominant dog" is focused on the customer needs of a main customer segment which is responsible for the main part of their profit. At the same time, the "mainstream market" is neglected. The start-up is offering C-customers something which is more beneficial to them and less expensive. The "dominant dog" is not reacting on this minor offer. The start-up is widening his market offers, more and more B- and A-customers and also former non-customers are using the new market offering. Has the start-up achieved the majority of the customers of the "dominant dog“", a "disruption" is formed [1]. 
Why are there that many examples, where established companies evolve into a victim of disruption? Why aren't they using their our opportunities much better? Examples of disruptions of today which shaked the future, were they foreseeable to a certain extent? The R\&D departments are in their routines, real innovation management is difficult in high regimented and high business processed corporations.

Corporate incubators and corporate accelerators should fill out the gap between the obstacles in corporations and the reality. They have only emerged in Germany in the last few years. While predecessors were focused on the supply of lowcost office space [2], the objectives of corporate incubators are nowadays very diverse:

- Identifying new business ideas and business areas

- Creating innovative market offers through targeted promotion of new business ideas and development of a culture of innovation

- Enhancing the employer branding by creating an attractive in-house environment for "free spirits" with the goal to recruit new talents and to retain existing talents

- Fertilizing the own enterprise with entrepreneurship and new yet proven methods

This study defines the two terms as follows: Incubators are companies that support the early phase of a start-up in form of infrastructure or framework conditions. Team and business idea are typically not fully known at this stage.

Accelerators are companies that engage in concrete business ideas; often a prototype is already available. They provide access to investor and mentor networks as well as occasionally to qualification measures.

\section{Methodology Approach for New Knowledge}

The content of the empirical study was the topic "Corporate Incubators and Corporate Accelerators within the technical/scientific/IT environment". It was designed as a qualitative study and conducted with semi-structured interview guidelines. The interviews took place personally. Altogether 17 Corporate Incubators/Corporate Accelerators were interviewed out of 28 possible incubators and accelerators with this special focus at the time of the execution. All of them in Germany, most of them with sales more than $€ 1$ bn., generally with more than 1.000 employees.

The interviews took place between April 2016 and August 2016.

The core questions as guideline for the interviews were [3]:

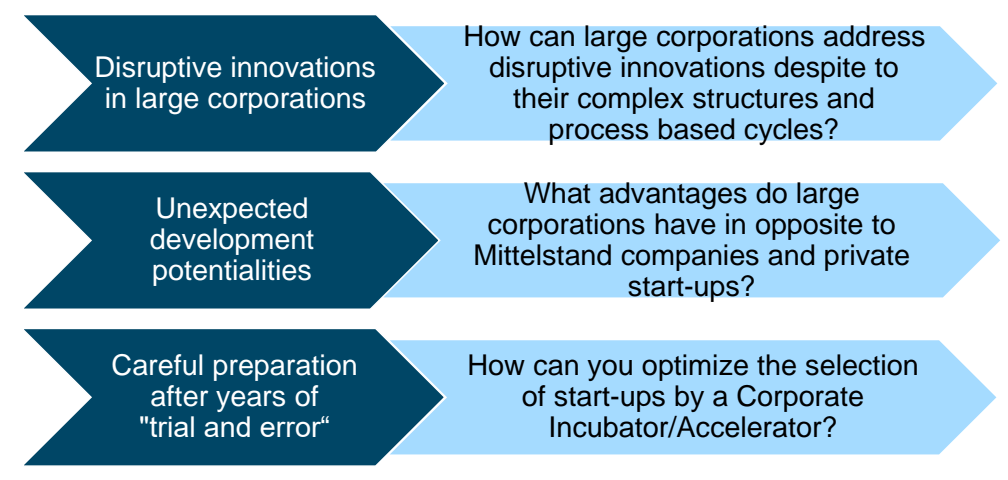

Fig. 1. Core questions of the study

\section{Innovation with Incubation - Expectations of Corporations}

Why do corporations invest millions of Euro in corporate incubation and acceleration? Their expectations of the corporations can be summarized into three points:

1. There is an objective to anticipate future innovations in a very early stage and to be a part of it: New ideas you could not follow up in daily business, it is also a possibility to keep internal employees with great ideas within the company, you get an understanding what developments are important and should be supported and you learn, how to place new sustainable business models into the market. In addition, to launch innovations in big corporations is a recipe, to avoid a "fat cat" position.

2. It provides more "Entrepreneurial Spirit" in the own company and is deleting the contradiction "Entrepreneur in a big corporation". Sometimes, companies a are heading towards a cultural change and the "Entrepreneurial Spirit" supports new opportunities based on one technology through increasing own inspiration and support of Intrapreneurship. From an organizational point of view, incubators, especially with own legal entity, avoid an integration in other business 
units but let them run on their own. Altogether, corporations want to create a start-up culture, learn from start-ups, recruit the people form start-ups.

3. Finally, of course, it is a tool to generate innovations. A start-up is generally a place to create new ideas and new field of businesses, simply a source for new topics within a corporation. Corporations today are trying to develop an innovative culture with product innovations and an innovation pool for new topics as a result. It is also important to have a possibility for diffusion of innovations in the whole company, therefore it must be known in all units of the company. And finally they have a better chance here to recognize disruptive innovations and use them early enough.

\section{Recommendations for Innovation within Corporations}

\subsection{A Good Team is more important than Technology}

The focus lies almost exclusively on start-ups that are founded in a team, normally between 3 and 4 people. Exceptions are rarely allowed. Due to the complexity of new business ideas, a team is necessary for realization and will generally be able to realize more than one person alone [4]. Thus, a multidisciplinary team is often more important than the actual business idea: innovations are created by overlapping different areas: Innovations may arise today through interacting industries, e.g. autonomous driving is combining the knowledge of computing, AI, sensors and others. The personality of the founders is of vast importance: What did the persons do in the past? The existing network, the professional background and the motivation of the persons involved are assessed! One of the team members will have to be communicative and able to sell the ideas! Corporate incubators can also actively get involved in configuring the team: this can be the case if the business idea is promising, but the fit of the team is not optimal. The team itself is often unable to do so, given that the social ties are often too close.

\subsection{Importance of the Business Model}

The business model does not have the importance that you might suspect. The individual elements of a business model are assessed, yet they do not have to be complete. The key question is rather: Can the individual elements in the business model evolve? The business model is understood rather as "structured thinking", which also shows a "feeling for market and customers". Another reason may be that it is considered as normal, when start-ups walk away from their initial business idea and focus on something else. One out of four start-ups changes drastically his business concept! Often the market offer only arises from the second or third derivative of the original project, one corporate incubator reported [5]. Business model innovations are more of an exception. This potentially disregards a good source for new business opportunities [6].

\subsection{Search for People with Smart Ideas}

The Corporate Incubators search for people who might serve a well-defined search business field of the company. The try to reach them through contests, call for bids but also through personal approaches via direct email, telephone: "People they care are contacted directly!" The big brands may receive interest of the start-up community because they are wellknown and progressive. And finally for the people in start-ups, it is very attractive to working together with them.

\section{4. "Strategic Fit" as a Must}

It is not the unlimited search for new ideas that define a corporate incubator, but rather the clear focus in a particular direction in which the company is interested: [7]:

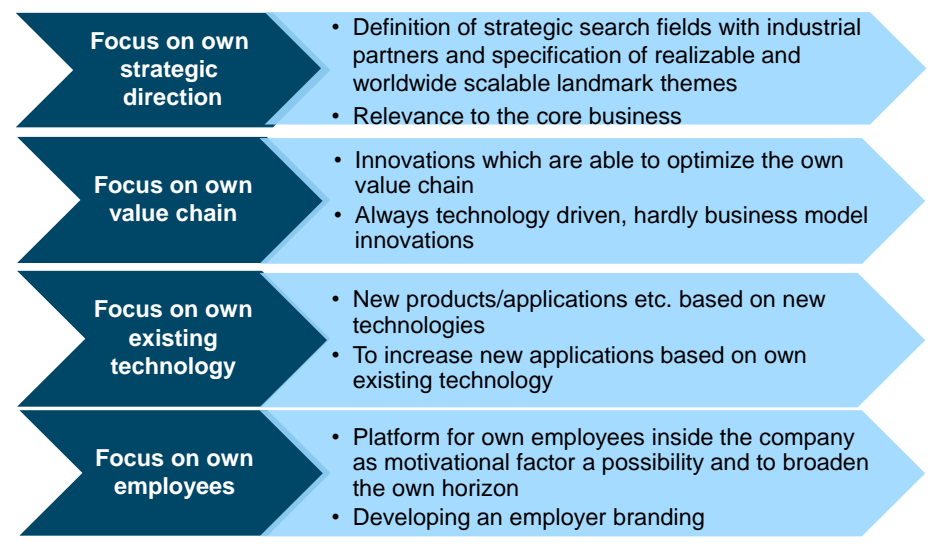

Fig. 2. Typical "Search Fields" show the Innovative Direction 
The "evaluation with on-board resources" is important; you would like to know the respective target markets! The focus on innovation is set at corporate incubators. This is binding; exceptions are rarely allowed, as otherwise the evaluation of business ideas becomes more complex. A ,strategic fit“ is required on almost all engagements. The incubator/acceleratorprograms of the companies are limited to their existing markets - a weakness [8]?

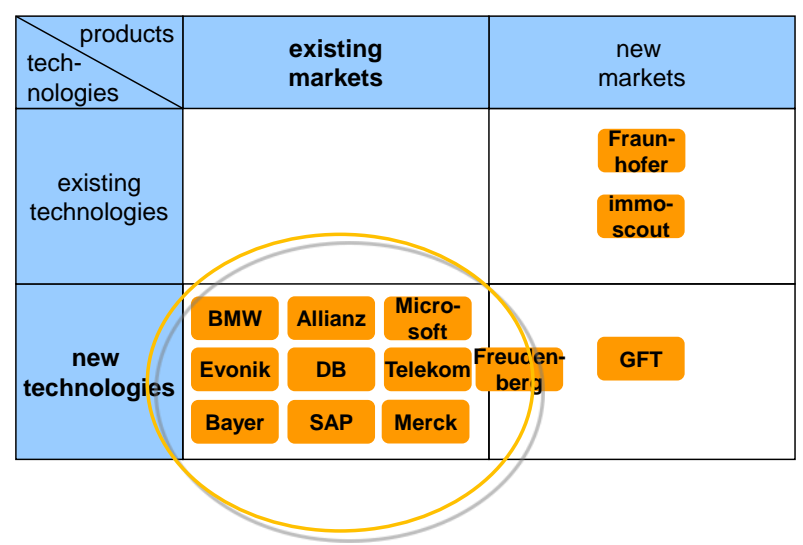

Fig. 3. "Strategic Fit" as pre-assumption

\subsection{Market Access and Market Opportunities in the Center}

Right from the start the team must also have an understanding of how to generate revenues! This requires a person in the team who knows the market "from the inside", i.e. comes from the industry. That way a "feel for the market and customer" is existent right from the start [9]. The core idea is quickly confronted with the market: small series of interviews with potential customers are carried out. "People meet people": talk to 20 customers and ask if they are willing to test a prototype - this will however cost EUR 50 per month for insurance. As soon as costs arise, the company will focus on benefits, go through different internal processes and make more rational choices! The opinion of friends who buy the offer just because they want to do a favor will not be sufficient. A true market test is preferred. Technology needs "use cases" [10]:

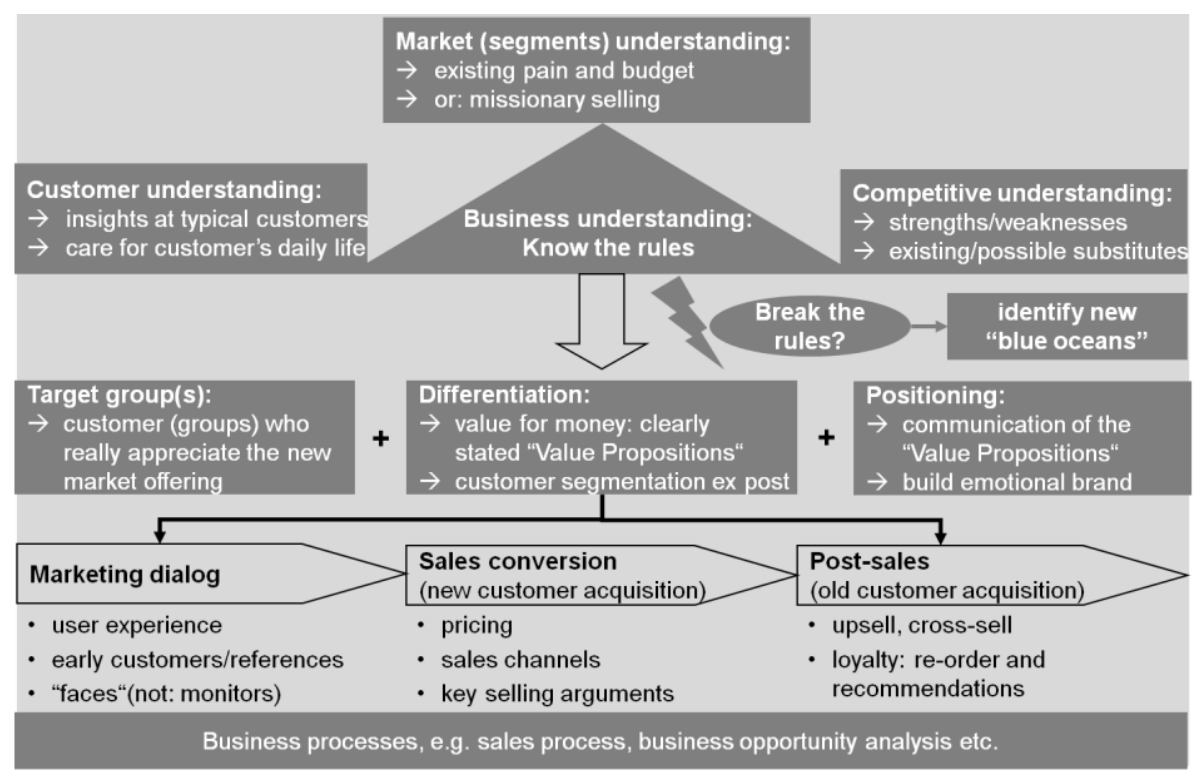

Fig. 4. Innovation requires Commercialzation

\section{Ten Key Messages for Innovation through Incubation}

1. Team beats technology: A good team can handle a lot; just a good technology without the team does not do much.

2. In the incubator/accelerator programs of companies, new business areas are the exception, almost always a certain proximity to the existing business is given. Is it really intended to pass on input from other industries?

3. When assessing start-up candidates, you should focus on the essentials, i.e. "B2B = back to basics": What is special, how can you make money from it, how is the service provided and who should buy it and why? 
4. A stronger focus on marketing and the awareness that wonderful business ideas are also finite. This requires responding to completely different types of customers at each stage.

6. Interaction in the new team of start-up talents and own corporate talents: Internal employees are brought together with experienced entrepreneurs coming from outside and the team works together to develop topics.

7. A few "lead users" do not constitute a mass market! Therefore, the "typical users" are more important, unless you deliberately choose a niche!

8. Working with the Business Model Canvas as a way to manifest the current state and to identify the gaps.

9. Methods must be known to the start-up, e.g. Business Model Canvas, Porter's 5-Forces to gain an overview of the industry structure and the competitive environment, the SWOT analysis to determine their own strengths and the resulting options for action, working with the "Buying Center" in the acquisition of new customers, and the "Business Opportunity" analysis to identify new business opportunities for new customers and later for existing customers.

10. Sooner or later, one will not get past KPIs for early risk minimization and criteria for exit, but also for measuring one's own success. So far, revenue is considered as an indicator for whether "it can work"!

\section{Conclusion}

It is hard to evaluate the sustainability of these Corporate Incubators, will they collapse in the face of an upcoming economic crisis, as in 2001 where many of the Corporate Venture Capital Companies disappeared? Or is it really considered as a main tool for generating innovations and will it have time to give evidence for that? There is no answer to these questions, but it is for sure that innovations are not waiting forever and they do not care about industry rules. They set their own ones.

\section{Acknowledgments}

At this point the author would like to thank the companies which were interviewed for the time and the insides which they provided. Many thanks to the grow platform $\mathrm{GmbH}$, a subsidiary of Robert Bosch GmbH, who supported this study.

\section{References}

[1] Christensen, C. (1997). The Innovator's Dilemma. When New Technologies Cause Great Firms to Fail, Boston

[2] Heinrichs, S.; Tischler, J. \& Walter, A. (2014). Leistungsprofile von Inkubatoren technologie-basierter Unternehmen: Eine empirische Bestandsaufnahme, Leibniz Information Centre for Economics

[3] Kohlert, H.; Rempel, I. (2017). Kohlert/Rempel: Benchmarking - Corporate Incubators und Accelerators in Deutschland Handlungsempfehlungen für Corporate Incubators und Corporate Accelerators - Eine empirische Studie, Esslingen

[4] Kohlert, H.; Fadai, D. \& Sachs, H.-U. (2013). Entrepreneurship for Engineers, München

[5] Disselkamp, M. (2017). Innovationen und Veränderungen, Stuttgart

[6] Kohlert, H. (2018). Vertriebsgrundlagen - Kunden verstehen und gewinnen, Stuttgart

[7] Kohlert, H. (2013). Marketing für Ingenieure, München 